\title{
Standardi dhe elbasanishtja
}

Elsa Boshku

\section{(Një vështrim i rrugëtimit të elbasanishtes, në përpjekjen e saj për t'u standardizuar)}

\begin{abstract}
Abstrakt
Ravijëzimi i një varianti të përbashkët gjuhësor që do të shërbejë si standard i një gjuhe të caktuar, për nga vetë funksionet e shumëfishta dhe simbolikës që mbart, rrallëherë ka ndodhur të kalojë pa debate e diskutime. Një ndër mënyrat se si mund të përzgjidhet ky variant është edhe ajo e ngritjes në normë të njërit prej dialekteve të një gjuhe, gjë që ka ndodhur edhe në rastin e shqipes me dialektin tosk. Kuptohet që edhe në rastin e gjuhës sonë, rruga deri në përsosjen strukturore e funksionore të standardit, kushtëzuar edhe nga rrethanat jashtëgjuhësore, nuk ka qenë e lehtë. Ajo është karakterizuar nga debate, diskutime e propozime të ndryshme, ndër të cilat, edhe ajo e vendosjes së elbasanishtes, si e tillë. Një vështrim historik i rrugës nëpër të cilën ka ecur standardi i shqipes deri në finalizimin e tij, na lejon të shohim më specifikisht rolin e elbasanishtes në këtë proces. Qëndrimet, arsyet pse kjo e folme mund të ishte një variant i mundshëm, si dhe mospërzgjedhja e saj, përpos të tjerave, na ofrojnë edhe modelet e orientimet e nevojshme për të shmangur situata të ngjashme të ndodhura më parë, aq më tepër sot, kur debati rreth standardit është rihapur sërish.
\end{abstract}

Fjalëkyçe: standard, elbasanishte, dialekt, variant. 


\section{Albanon}

Revistë kulturore

\section{Hyrje}

Krijimi i një varianti të përbashkët në gjuhën shqipe, siç është standardi, ashtu sikurse edhe në çdo gjuhë tjetër, u formësua brenda kornizës së disa rrethanave gjuhësore, sociale dhe historike. Kuptohet që një çështje me një nivel kaq të lartë rëndësie për një popull, nuk mbetej vetëm në kufijtë e problematikave thjesht gjuhësore. Kjo, edhe për vetë faktin që funksionet e tij apo edhe simbolika që mbart e kalojnë këtë cak, e për këtë arsye, pati diskutime dhe debate të vazhdueshme, të cilat, vazhdojnë edhe sot.

Është mjaft i njohur fakti që një nga mënyrat e formimit të standardit të një gjuhe është nëpërmjet ngritjes në normë të njërit prej dialekteve të saj. E njëjta praktikë ka ndodhur edhe me gjuhën shqipe, e cila, është ndërtuar mbi bazën e dialektit tosk, por para tij, një mendim mjaft i mbështetur ka qenë elbasanishtja dhe prej këtej morëm idenë e objektit të këtij punimi.

Procesi i krijimit të gjuhës shqipe standarde ka kaluar nëpër disa etapa në të cilat, faktorët e jashtëm shoqërorë, bashkë me faktorët e brendshëm gjuhësorë, janë ata që kanë përcaktuar edhe rrugën e formimit të gjuhës letrare kombëtare shqipe. ${ }^{1}$

Në këtë punim, bazuar në periodizimin e rrugës së formimit të gjuhës shqipe, të kryer nga studiuesit M. Samara dhe A. Kostallari, të cilët dallojnë dy periudha: parakombëtare dhe kombëtare, jemi munduar që të ndalemi në veçanti, në pozicionin dhe rolin e elbasanishtes në këtë rrugëtim.

\section{Periudha parakombëtare}

Periudha parakombëtare, nis që nga "Formula e Pagëzimit", duke u pasuar më tej me dokumentet dhe tekstet e para shqipe të Buzukut, L. Matrëngës, P. Budit, F. Bardhit, P. Bogdanit. Më tej kemi shqipen e shkruar në shek. XVIII, periudhë në të cilën ajo vazhdoi të funksiononte më tepër si gjuhë e letërsisë kishtare.

Gjatë kësaj kohe, varianti më i përdorur ka qenë ai i gegërishtes, në të cilin kemi edhe shumicën e dokumentave të lashta të shkrimeve shqipe. Vetëm nga fundi i shek. të XIX, nis të zgjerojë funksionet e veta toskërishtja.

Sa i përket formësimit të një varianti standard gjatë kësaj periudhe, megjithëse kjo e fundit mjaftueshëm e gjatë, nuk paraqitet ndonjë zhvillim. Kuptohet që nuk mund të flasim për asnjë ngjarje lidhur me elbasanishten.

1 Miço Samara, Formimi i gjuhës letrare kombëtare shqipe, Tiranë, 1989, f. 25. 


\section{Periudha kombëtare}

Periudha e dytë është ajo kombëtare. Kjo periudhë fillon prej viteve '60 e deri në vitet' 90 .

Duke u mbështetur në veçoritë historike, shoqërore e gjuhësore, ajo ndahet në tri etapa. Të tria këto etapa, siç shprehet edhe Kostallari, “në të cilat kanë ecur krahas edhe lëvrimi, edhe studimi $i$ shqipes letrare, i bashkon një vijë e vetme zhvillimi - vija e konvegjencës gjuhësore gjithnjë në rritje e pa kthime mbrapa, e cila ka pasur si mbështetje konvergjencën kombëtare ekonomikoshoqërore, politike e kulturore"2. Pikërisht, përgjatë panoramës historike dhe vëzhgimit të klasifikimit të këtyre etapave, sipas M. Samarës dhe A. Kostallarit do të mundohemi të shohim edhe pozicionin e elbasanishtes si variant i mundshëm për të qenë baza e formimit të gjuhës standarde dhe arsyet e (mos)përzgjedhjes së këtij varianti.

\section{Etapa e pare (vitet '6o të shek.XIX deri më 1912)}

Në etapën e parë, u hodhën themelet e gjuhës letrare shqipe dhe u ravijëzua drejtimi i zhvillimit të saj. Lidhja e Prizrenit, themelimi i Shoqërisë së Stambollit, përpjekjet për të krijuar alfabete origjinale dhe për të futur shqipen në shkolla u bënë faktorë mjaft të rëndësishëm, që i hapën rrugë zhvillimit të gjuhës letrare shqipe. Produkt i punës madhore të rilindasve ishte krijimi i një letërsie të gjërë artistike, didaktiko-shkencore e publicistike, e cila u pasua edhe nga studimi i strukturës gramatikore, si edhe nga mbledhja e përpunimi i leksikut të shqipes. Përmendim këtu gramatikat e K. Kristoforidhit e të S. Frashërit dhe po ashtu veprën "Fjalori i gjuhës shqipe” të Kristoforidhit. Gjatë kësaj etape puna për zhvillimin dhe lëvrimin e gjuhës shqipe mori karakter të organizuar. Arritja e parë ishte pikërisht hapja e shkollës së parë në gjuhën amtare në Korçë, më 7 mars 1887, e cila u pasua edhe nga shkolla të tjera në Korçë, Dibër, Mat, Tiranë, Elbasan etj. Një rezultat tjetër i rëndësishëm që solli Rilindja në fushën e gjuhës, ishte krijimi i alfabetit unik të shqipes më 1908 në Kongresin e Manastirit.

Ndryshe nga sa u pa në periudhën parakombëtare, në vend të shumë varianteve shkrimore, në këtë etapë, u krijuan dy variante letrare mbi dy baza dialektore: varianti letrar jugor dhe varianti letrar verior i shprehur

2 Androkli Kostallari, Gjuha e sotme letrare shqipe dhe disa probleme themelore të drejtshkrimit, në Kongresi i Drejtëshkrimit të gjuhës shqipe, II Tiranë, 1973, f. 67. 


\section{Albanon}

\section{Revistë kulturore}

në dy bashkëvariante: në bashkëvariantin e mesëm ose gegërishten jugore (elbasanishten) dhe në bashkëvariantin veriperëndimor (shkodranishten).

Ndërsa deri në prag të Rilindjes, epërsinë e kishte varianti i gegërishtes, Rilindja solli një përmbysje të këtij raporti duke i hapur rrugë mendimeve për të vënë toskërishten në bazë të gjuhës letrare kombëtare, meqë ajo arriti të formohej si një koine letrare gjithëjugore.

Një vend të rëndësishëm në këtë fazë e që lidhet drejtpërdrejt me çështjen që kemi marrë për të diskutuar, zënë të dhënat që lidhen me Kongresin e Elbasanit (1909), në të cilin për herë të parë trajtohet ideja e krijimit të një gjuhe të përbashkët, ide e cila, pas shumë shqyrtimesh, përfundon edhe me një vendim të veçantë.

Në vetvete, kishim të bënim më një kongres arsimor, i cili, përveç çështjeve që lidheshin me arsimin, trajtoi edhe problematikën mbi alfabetin dhe shqipen e përbashkët.

Ky kongres përbëhej nga një sërë delegatësh, midis të cilëve atdhetarë e veprimtarë, gjuhëtarë e figura të shquara, si: Simon Shuteriqi, Thoma Papapano, Gjergj Qiriazi, Sevasti Qiriazi, Dhimitër Buda, Nikollë Kaçorri, Orhan Pojani etj. Këtu iu dha përparësi idesë që të mbrohej e të zbatohej alfabeti i vendosur në Kongresin e Manastirit dhe të luftohej përdorimi i alfabetit arab për të shkruar gjuhën amtare.

Nisur nga fakti që elbasanishtja ishte e kuptueshme nga të gjithë, kongresi vendosi që ajo të shërbente si gjuhë letrare (standarde) për shqiptarët. Ky vendim u pasqyrua gjerësisht edhe në shtypin e kohës. Në gazetën "Lirija", botuar në Selanik më 1909, vendimi pasqyrohet në këtë formë: "Kongresi u dorëzon të gjithë shkrimtarëvet shqiptarë që të përdorin në shkrimet të tyre, me sa t’u mundet dialektin e Elbasanit, sepse është dialekt që kuptohet me gjith anët të Shqipnisë3

Në të përkohshmen periodike të Manastirit “Bashkimi i Kombit” shkruhej që në Kongresin e Elbasanit një numër i konsiderueshëm i delegatëve shfaqën mendimin që si gjuhë letrare për shqipen të jetë e folmja e elbasanishtes. Një propozim i tillë argumentohej me faktin se e folmja e Elbasanit është më e afërt për të dy dialektet e gjuhës shqipe të veriut dhe të jugut dhe si më e afërt e më e kuptueshme për shqiptarët e të githa viseve.

Siç shihet, edhe në këtë interpretim, vihet re fakti që rëndësi parësore në këtë

3 Alfabeti i gjuhës shqipe dhe Kongresi i Manastirit, Universiteti i Shkencave të Tiranës, Instituti i Historisë dhe i Gjuhësisë, Tiranë, 1972, f. 251. 
përzgjedhje merr pikërisht të kuptuarit e të folmes së Elbasanit nga të gjithë shqiptarët. ${ }^{4}$

Pavarësisht mbështetjes së gjerë që gjeti ky vendim, nuk mungonin edhe idetë e kundërta. Lidhur me këtë vendim, Aleksandër Xhuvani, mban qëndrimin e përfshirjes së aspekteve të veçanta të të dy dialekteve: të vendoset toskërishtja si bazë letrare, por e shkruar me shkronjat e shoqërisë "Bashkimi”. Ndër të tjera ai shprehet: "Mendja ime asht këjo: për themelim të nji gjuhe letërare, të mirret toskënishtja; për shkronjat të nji abeje të përgjithshme, të mirren shkronjat e shoqnis së "Bashkimit”. Me kët mënyrë më duket qi të dy palëvet nuk do t'u vi keq, sepse toskët më nj"anë do apinë dialektin e vet për gjuhë letërare, më tjetër anë gegët, vepr'e të cilëve quhet "Bashkimi" do apinë shkronjat e veta të cilat sot janë më të pëlqyeshme dhe ma të përdoruëme prej ma të shumëve shkrimtare". ${ }^{5}$ Sidoqoftë, vendimet e Kongresit të Elbasanit u pranuan gjerësisht, dhe më në fund u përcaktua modeli gjuhësor bazë i përbashkët për të gjithë shqiptarët. Një fakt i cili kërkon vëmendjen e duhur në këtë pikë, lidhet edhe me rrugët që përcaktoi Kongresi i Elbasanit për përhapjen e elbasanishtes, të cilat, ishin kryesisht nëpërmjet librave, shtypit e dokumentave zyrtare, si dhe nëpërmjet shkollës Normale, e cila u hap në vjeshtën e vitit 1909, prej ku mësonin nxënës nga të gjitha trevat. Sidoqoftë, pavarësisht arrtitjeve e kundërshtive, mund të pohojmë që ky Kongres i arriti qëllimet e tij për gjuhën dhe arsimin shqiptar, në një periudhë kur këto çështje ishin jetike për shqiptarët dhe Shqipërinë.

Vendimi i marrë në Kongresin e Elbasanit lidhur me elbasanishten si gjuhë e përbashkët, duket se nuk u praktikua vetëm nga autorët elbasanas, por edhe nga albanologë të huaj, ndër të cilët po përmendim Gustav Vajgandin. Ky albanolog e shkroi Gramatikën e tij (1913) duke përdorur variantin gjuhësor të elbasanishtes.

\section{Etapa e dytë (nga viti 1912 e deri më 1944)}

Etapa e dytë në historinë e gjuhës standarde shqipe fillon pikërisht me fillimin e krijimit të shtetit shqiptar, një hap historik, i cili, padyshim të shpinte drejt domosdoshmërisë së krijimit të një varianti gjuhësor të përbashkët të shqipes.

\footnotetext{
4 Ali Visko, Përpjekjet për gjuhën letrare dhe për alfabetin e njësuar të shqipes në vitet 1908-1910, në Konferenca shkencore "Gjuha letrare kombëtare dhe bota shqiptare sot", Tiranë, 20-21 nëntor 1992, f. 229.

5 Alfabeti i gjuhës shqipe dhe Kongresi i Manastirit, Universiteti i Shkencave të Tiranës, Instituti i Historisë dhe i Gjuhësisë, Tiranë, 1972, f. 191.
} 


\section{Albanon}

\section{Revistë kulturore}

Kjo etapë ndahet në tri faza:

- Faza e parë fillon nga viti 1912 dhe shkon deri në vitin 1923, atëherë kur shteti shqiptar shpalli me dekret elbasanishten, si gjuhë zyrtare shtetërore.

- Faza e dytë fillon nga viti 1923 dhe vazhdon deri në vitin 1939 (periudha e pushtimit të Shqipërisë nga Italia).

- Faza e tretë fillon nga viti 1939 dhe vazhdon deri në vitin 1944.

Faza e parë: Kjo fazë përkon me Komisinë Letrare të Shkodrës, si një institucion, i cili i dha një shtysë të mëtejshme procesit të krijimit të gjuhës standarde shqipe, sidomos, variantit të elbasanishtes në veçanti. Ajo u themelua më 1 shtator 1916 dhe përbën një moment kyç për shqipen dhe kombin shqiptar. Qëllimi themelor i Komisisë ishte zgjidhja një herë e përgjithmonë e çështjes së drejtshkrimit të shqipes, si dhe e përcaktimit të variantit gjuhësor, mbi të cilin, do të mbështetej shqipja standarde. Ky komision gjuhëtarësh e shkrimtarësh, rimori vendimin e Kongresit të Elbasanit, duke vlerësuar variantin letrar të mesëm, elbasanishten, si një urë në mes toskërishtes dhe gegërishtes. Komisioni përcaktoi, gjithashtu, edhe një tërësi rregullash për drejtshkrimin e këtij varianti, të cilat ndikuan në njësimin e shqipes së shkruar. Në të morën pjesë një sërë përfaqësuesish, patriotë e personalitete të jetës e të kulturës kombëtare, si: Luigj Gurakuqi, Gjergj Pekmezi, Ndre Mjeda, Mati Logoreci, Sotir Peci, Hilë Mosi, Aleksandër Xhuvani, Gjergj Fishta, Luigj Naraçi, Ndue Paluca, Ambros Marlaskaj, Rajko Nachtigal dhe Maximilian Lambertz. Çështja e krijimit të një gjuhe të përbashkët u hap së pari me mbledhjen e 11 dhjetorit 1916, dhe përbënte në vetvete një çështje me rëndësi themelore. Kryetari i Komisisë ishte Gj. Pekmezi. Ndërkohë, Luigj Gurakuqi, kërkonte që të zgjidhej një dialekt që të ishte "si urë lidhëse në mes të dy dialekteve". ${ }^{6}$

Sidoqoftë, ndonëse ishte përkrahës i kësaj ideje, shprehej se nuk e pëlqente të folmen e Elbasanit ashtu siç ishte, ndaj sipas tij, duheshin gjetur forma të mesme me përmirësime "për ti futurë në gjuhën e përbashkët". Në diskutim u përfshinë dhe shumë anëtarë të tjerë. Fishta, njëri nga anëtarët me mjaft influencë në Komisi, nuk e kundërshtoi një ide të tillë.

6 Tomorr Osmani, Ngjarje me rëndësi e kulturës sonë-Komisia Letrare Shqipe në Shkodër (1916-1917), në Gjurmime albanologjike, seria e shkencave filologjike 28-29, Instituti albanologjik i Prishtinës, Prishtinë 2002, f. 60.

7 Po aty. 
Nëse do të bënim një përmbledhje të qëndrimeve e mendimeve të shfaqura në Komisi lidhur me problemin e krijimit të një gjuhe standarde të përbashkët dhe të bazës së saj dialektore, do të dallonim qartë dy grupime kryesore:

- Njëri grup mendonte të mbahej një sistem dygjuhësh letrare: gegërishtja me bazë shkodranishten dhe toskërishtja letrare.

- Grupi tjetër mbështetej prej Luigj Gurakuqit i cili propozonte dialektin e Shqipërisë së mesme ose elbasanishten për ta vënë në bazë të gjuhës standarde shqipe. Në këtë rrjedhë të menduari ishte edhe dijetari Gustav Vajgand, i cili pohonte: "Dialekti i gegërishtes së jugës, i cili nukë duhet të konsiderohet si një dialekt i përzjerë toskërisht e gegërisht, po në gjendjen e tij fonetike përmbledh të gjitha karakteristikat e gegërishtes; nukë është vetëm $i$ kuptuarshëm për të gjithë Shqipëtarët, po edhe dialekti që munt të mësohet më lehtë. Thjeshtësia e lakimit t'emërit e të përemërit kundrejt trajtave të shumta të toskërishtes, numëri i pakët i trajtave verbale, participi i shkurtër, të gjitha këto janë lehtësime të mjafta për të mësuar gegërishten e jugës kundrejt toskërishtes". ${ }^{8}$ Studiuesi gjerman, Georg von Hahn, ishte i mendimit që e ardhmja e gjuhës sonë të përbashkët duhet kërkuar atje "ku nukë munt të bëhet një ndarje e prerë në mes gegërishtes e toskërishtes, $e$ ku elemenët e të dy dialekteve kryesore afrohen e përzjehen". Pra, qëndrimi i tij të lë të kuptosh që ky albanolog ishte gjithashtu për elbasanishten letrare. Pas debateve shkencore të shumta u vendos dhe u miratua për përzgjedhjen e dialektit të Elbasanit si gjuhë shkrimi. Megjithatë, Komisia nuk e arriti suksesin e dëshiruar. Gjuha e përbashkët, e miratuar nga ky institucion, pësoi fatin e alfabetit të Shoqërisë së të Shtypurit Shkronja Shqip të Stambollit.

Gjatë fazës së dytë të etapës së dytë rimerret çështja e vendosjes së elbasanishtes si gjuhë e përbashkët për të gjithë shqiptarët. Më 13 janar të vitit 1923, shteti nxjerr dekretin që: si gjuhë zyrtare shtetërore të përdorej bashkëvarianti i gegërishtes jugore ose elbasanishtja. Kryeministria kishte autorizuar administratën shtetërore që "për bazë të gjuhës së shkruar zyrtare të kishte të folmen e Elbasanit” dhe për më tepër, jepej urdhri që në "... gjith zyrat në shkrim të akteve zyrtare gjithmon të përdoret djalekti i Elbasanit”"10. Pra, teza për të vënë elbasanishten në bazë të gjuhës letrare kombëtare, shfaqet në mënyrë zyrtare.

8 Rexhep Ismajli, Gjuhë standarde dhe histori identitetesh, Tiranë, 2005, f. 71.

9 Po aty.

10 Mehmet Çeliku, Çështje të shqipes standarde, Tiranë, 2009, f. 124. 


\section{Albanon}

\section{Revistë kulturore}

Nëse pritshmëria, ishte pa hezitim për përdorimin në masë të gjerë të këtij varianti, tashmë zyrtar, situata e përditshme shkrimore shqiptare shfaqej kontradiktore.

Përditshmëria tregonte që varianti letrar më i përdorshëm me funksione të gjera shoqërore dhe i përhapur, sidomos në botimet që përfaqësonin letërsinë artistike të kohës, ishte koineja letrare toske. Kjo koine vazhdonte të zhvillohej, duke e përforcuar karakterin e saj si koine gjithëjugore. Por cilat ishin disa nga arsyet e shmangies nga elbasanishtja?

Ndër të tjera mund të përmendim:

1. Toskërishtja pati një përhapje më të gjërë në shkrim; u botuan shumë periodikë e botime artistike në këtë variant dhe po ashtu toskërishtja shfaqej më e njësuar.

2. Vendimi i Komisisë Letrare u sabotua menjëherë nga kleri katolik, ato u ngritën kundër vendimeve të Komisisë Letrare e atyre të Kongreseve arsimore.

3. Një tjetër faktor lidhet me vetë Komisinë Letrare të Shkodrës e cila e përqendroi vëmendjen në gjuhën e shkollës dhe të administratës. Rrallë u fol edhe për gjuhën e letërsisë.

4. Nuk ekzistonte një traditë letrare e pasur në këtë varietet, si dhe ndonjë institucion i caktuar që përmes reputacionit të tij të kishte mundur t’i vinte në ndihmë normës së re standarde për t’u pranuar nga të gjithë.

5. Rrethanat historike e shoqërore-administrative të pafavorshme në atë periudhë, si: ndërrimet e qeverive apo luftërat e trazirat e shumta që shoqëruan kombin shqiptar.

6. Mbështetjen e dobët nga masa intelektuale dhe nga organizmat shtetërorë - institucionalë.

Faza e tretë: Në këtë fazë kemi Kuvendin Albanologjik italo-shqiptar, mbajtur në vitin 1940 dhe Kuvendin e Parë Albanologjik të Institutit të Studimeve në Tiranë, të organizuar më 9-12 prill 1940.

Ajo çka i lidh këto dy Kuvende është fakti që ende vazhdon të diskutohet çështja e variantit standard të shqipes. Vihet re një qëndrim pro përkundrejt gegërishtes dhe, në veçanti elbasanishtes, pavarësisht kundërshtive. Sidoqoftë, në këtë Kuvend, nuk u arrit dhe nuk u soll asnjë risi, për krijimin e gjuhës standarde shqipe. 


\section{Etapa e tretë (nga viti 1944 e deri në ditët tona)}

Etapa e tretë, përbën momentin vendimtar për formimin e gjuhës standarde shqipe. Ajo ndahet në tri faza që përfshijnë periudhën kohore nga viti 1944 e deri në vitin 1990.

Në fazën e parë një vend të rëndësishëm zë trajtimi i disa vendimeve të menjëhershme për heqjen nga përdorimi të gegërishtes në shtypin e shkruar e, më pas, edhe nëpër shkolla (1945-1946), si dhe vendimi për zhvillimin e mësimit në toskërisht.

U zhvilluan dy sesione rreth kësaj çështje në vitin 1952. Në sesionin e parë bien në sy qëndrimi i Dhimitër Shuteriqit, Aleksandër Xhuvanit, si dhe i Lirak Dodbibës, të cilët paraqitnin arsye për vendosjen e toskërishtes si bazë e krijimit të gjuhës standarde shqipe.

E njëjta problematikë shfaqet edhe në sesionin e dytë. Spikatin në të mendimi i mbajtur nga Shuteriqi, i cili nxirrte në pah faktin që dialekti i jugut ishte dialekti më i shkruar deri në periudhën para çlirimit dhe kjo shpjegohej me zhvillimin më të madh ekonomiko-shoqëror të jugut të Shqipërisë në krahasim me veriun". ${ }^{11}$ Po kështu spikat edhe mendimi i Xhuvanit, që pas shumë përsiatjesh mban po të njëjtin qëndrim me Shuteriqin, përsa i përket toskërishtes si variant i përbashkët.

Në fazën e dytë, Kongresi i Drejtshkrimit (1972), e zgjidh në mënyrë përfundimtare çështjen e krijimit të gjuhës standarde shqipe, bazuar në variantin e toskërishtes.

Faza e tretë ngërthen në vetvete ato çështje që lidhen me përsosjen strukturore e funksionale të gjuhës standarde shqipe, si dhe ngulitjen e normës letrare të njësuar. Në këtë pikë merr fund rrugëtimi i gjatë i diskutimeve lidhur me këtë problematikë dhe fillon botimi i një sërë veprash gjuhësore. Tashmë, shqipja përfshihet në një proces mjaft të rëndësishëm, në atë të institucionalizimit të standardit të saj.

Me këto zhvillime përmbyllet trajtimi historik i procesit nëpër të cilin ka kaluar formimi i gjuhës standarde shqipe që në fillesat e para e deri në vitet '90.

11 Rexhep Ismajli, Gjuhë standarde dhe histori identitetesh, Tiranë, 2005, f. 127. 


\section{Albanon}

Revistë kulturore

\section{Përfundime}

1. Shqipja, pavarësisht rrethanave të vështira historike, politike, ekonomike e shoqërore, të cilat kryen rolin e tyre në vonesën e formësimit të një varianti letrar të përbashkët, mundi që t’i japë jetë, këtij të fundit, nëpërmjet vendosjes në bazë të tij, pranuar tashmë nga të gjithë studiuesit, variantin e toskërishtes.

2. Rruga nëpër të cilën kaloi kjo zgjedhje përfundimtare, vetëkuptohet se për nga rëndësia që mbart, është e mbushur me diskutime e debate të shumta që ende sot janë të gjalla. U propozuan disa variante, ndër të cilat ishte edhe elbasanishtja.

3. Vihet re se përgjithësisht, arsyeja kryesore që studiues shqiptarë dhe të huaj, ndër të cilët, Pekmezi, Gurakuqi, Vajgandi apo Hahni, e shohin elbasanishten si variantin më të mundshëm është, sepse e shohin atë si një të folme të ndërmjetme, e cila, kuptohet edhe nga folësit e toskërishtes, por edhe nga ata të gegërishtes.

4. Si ide, u hodh fillimisht gjatë etapës së parë kombëtare, në Kongresin e Elbasanit, prej nga u mbështet nga shumë studiues, si dhe u pasqyrua si vendim edhe në shtypin e kohës. Këtu u projektuan edhe format në të cilat do të përhapej kjo e folme: nëpërmjet librave, shtypit, Shkollës Normale etj.

5. Komisia e Shkodrës e çoi më tej akoma këtë vendim, i cili u mbështet edhe nga personalitete të shquara që ishin pjesëmarrës në të, përfshirë këtu edhe L. Gurakuqin, Gj. Fishtën etj. Megjithëse shohim se pavarësisht mbështetjes që i dhanë, shumë prej pjesëtarëve të Komisisë, nuk e zbatuan as vetë në realitet, këtë vendim.

6. Gjatë etapës së dytë, ndër ngjarjet më të rëndësishme, që lidhet me të folmen e elbasanishtes, do të ishte vendimi zyrtar i qeverisë ne vitin 1923, për ta shpallur tanimë zyrtarisht elbasanishten si gjuha që do të përdorej në institucionet zyrtare. Edhe pse e vendosur në formë zyrtare, ajo ç'ka ndodhi në realitet, është se ky vendim nuk u zbatua. Kishte një kontradiktë midis asaj ç'ka u vendos në formë zyrtare dhe realitetit.

7. Arsyet e kësaj shmangie nga elbasanishtja ishin disa, ndër të tjera, edhe mungesa e botimeve dhe mbështetja e institucioneve që do të mund të bënin përhapjen e saj, por edhe kushtet politike të Shqipërisë së asaj kohe. 
8. Ndërkohë toskërishtja gjatë kësaj kohe kishte krijuar kushtet e nevojshme që do ta bënin më vonë si variantin bazë, në të cilin do të mbështetej standardi. Kishte një numër të madh periodikësh që botoheshin në këtë variant dhe letërsi artistike, po ashtu. Jo vetëm nga ana sasiore, por toskërishtja dominoi edhe cilësisht. Ajo shfaqej edhe më e unifikuar se gegërishtja.

9. Këto dhe faktorë të tjerë, bënë që toskërishtja të vendosej në bazë të standardit të gjuhës shqipe dhe, në etapën e tretë të formimit të tij, $u$ jetësua me Kongresin e Drejtëshkrimit.

\section{Bibliografi}

Alfabeti i gjuhës shqipe dhe Kongresi i Manastirit, Universiteti i Shkencave të Tiranës.

Çeliku, M., Kongresi i Manastirit vështruar pas 100 vjetësh, "Çështje të shqipes”, Instituti i Historisë dhe i Gjuhësisë, Tiranë, 1972.

Ismajli, R., Gjuhë standarde dhe histori identitetesh, Tiranë, 2005.

Kostallari, A., Gjuha e sotme letrare shqipe dhe disa probleme themelore të drejtshkrimit të saj, Kongresi i Drejtëshkrimit të gjuhës shqipe, II, Tiranë,1973.

Lloshi, Xh., Kristoforidhi përmes dokumentimit, Tiranë, 2005. Osmani, T., Ngjarje me rëndësi e kulturës sonë - Komisia Letrare Shqipe në Shkodër (1916-1917), Gjurmime albanologjike, Instituti albanologjik i Prishtinës, Prishtinë 2002.

Samara, M., Formimi i gjuhës letrare kombëtare shqipe, Tiranë, 1989.

Visko, Ali., Përpjekjet për gjuhën letrare dhe për alfabetin e njësuar të shqipes në vitet 1908-1910, Konferenca shkencore "Gjuha letrare kombëtare dhe bota shqiptare sot", Tiranë, 20-

21 nëntor 1992. 